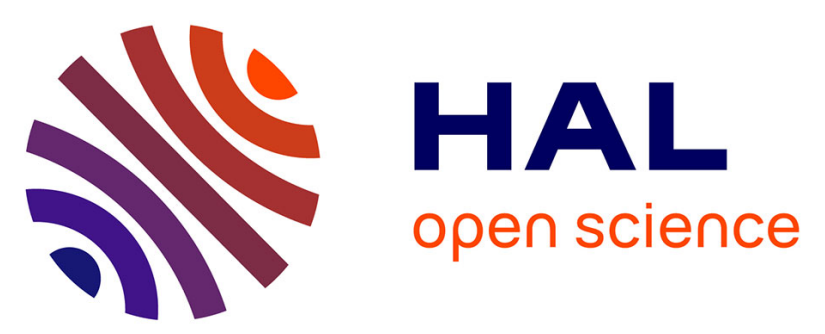

\title{
Measurements and modelling solid solubilities in supercritical phases: application to a pharmaceutical molecule, eflucimibe
}

\author{
Martial Sauceau, Jacques Fages
}

\section{- To cite this version:}

Martial Sauceau, Jacques Fages. Measurements and modelling solid solubilities in supercritical phases: application to a pharmaceutical molecule, eflucimibe. Trevor M Letcher. Developments and applications in solubility, The Royal Society of Chemistry, pp.292-304, 2007, 978-0-85404-372-9. 10.1039/9781847557681-00292 . hal-01730596v2

\section{HAL Id: hal-01730596 \\ https://imt-mines-albi.hal.science/hal-01730596v2}

Submitted on 16 Mar 2018

HAL is a multi-disciplinary open access archive for the deposit and dissemination of scientific research documents, whether they are published or not. The documents may come from teaching and research institutions in France or abroad, or from public or private research centers.
L'archive ouverte pluridisciplinaire HAL, est destinée au dépôt et à la diffusion de documents scientifiques de niveau recherche, publiés ou non, émanant des établissements d'enseignement et de recherche français ou étrangers, des laboratoires publics ou privés. 


\section{Measurements and Modelling Solid Solubilities in Supercritical Phases: Application to a Pharmaceutical Molecule, Eflucimibe}

M. SAUCEAU ${ }^{1}$ AND J. FAGES ${ }^{2}$

${ }^{1}$ Processium, Process Integration \& Technologies, 69622, Villeurbanne, France

${ }^{2}$ Laboratoire de Génie des Procédés des Solides Divisés, UMR CNRS 2392, École des Mines d'Albi-Carmaux, 81013, Albi, France

\subsection{Introduction}

Supercritical fluids (SCF) are widely used for a broad field of industrial applications. The interest in using this technology is due to the special properties that are inherent to this class of fluids: the viscosity and the diffusivity of a SCF which are found in between that of a gas and liquid and the ability to vary the solvent density and the solvent properties easily and over a large extent by changing either the pressure or the temperature.

The applications often involve solutes that are in solid state at conditions where the solvent is in a supercritical condition. Among these applications, the $\mathrm{SCF}$-assisted particle generation is a new and promising route to produce fine powders in mild operating conditions. It has attracted a lot of interest particularly in the pharmaceutical industry. ${ }^{1}$ By using pressure as an operating parameter, these processes lead to the production of fine and mono-disperse powders. There exist three families of processes (RESS, SAS, and PGSS) according to the way in which the FSC - generally $\mathrm{CO}_{2}$ - is used.

To develop them, the knowledge of the solid compound solubility in the corresponding involved medium is essential for evaluating the feasibility. Indeed, solubility is a good measurement of interactions between species. Moreover, the accurate determination of the influence of pressure and 
temperature on the solubility level provides insight into optimum operating conditions.

The most common SCF, carbon dioxide $\left(\mathrm{CO}_{2}\right)$, is easy to handle, inert, nontoxic, non-flammable, and has convenient critical coordinates. A limitation of $\mathrm{CO}_{2}$ results from its lack of polarity and associated lack of capacity for specific solvent-solute interactions. For most high molecular weight compounds (nonvolatile organic compounds), the solubility in supercritical $\mathrm{CO}_{2}$ is quite low requiring high temperatures and pressures for substantial loadings. Thus, there is a great incentive to improve solvent efficiency. For these purposes, small amounts of a highly polar co-solvent can be added to $\mathrm{CO}_{2}$ in order to increase its solvating power. The choice of a co-solvent depends not only on its ability to enhance solubility but also on its availability in high purity and its physicochemical characteristics. In particular, for pharmaceutical purposes, the cosolvent must be also non-toxic.

Progress has been made towards the understanding of the interactions involved in dilute supercritical mixtures. It has been shown that near the critical point of a SCF solution, the solvent molecules form "clusters" around the large solute molecules to form a local density that is higher than the bulk density. ${ }^{2}$ When a co-solvent is added, the situation is further complicated by the differences in local and bulk compositions. ${ }^{3}$

Several experimental techniques have been developed to investigate highpressure equilibria. ${ }^{4}$ There exist two types of methods according to the way the composition is measured, the synthetic methods and the analytical methods. Synthetic methods involve indirect determination of equilibrium composition without sampling. They require preparing systems of given total composition according to each point in the $(T, x)$ or $(P, x)$ diagrams, and therefore, are time consuming. In analytical methods, the composition of the phases in equilibrium is obtained by analyses after sampling. These methods are most widely used to determine solid-fluid equilibrium.

Because of the limited amount of experimental data dealing with solid-SCF systems, there has been considerable interest in mathematical models that can accurately predict the phase behaviour of such systems. Some of the commonly used models that have been used with some success to correlate solid solubility data include equations of state (EoS). However, such models often require properties (such as critical temperature, critical pressure, and acentric factor) that are not available for most of solid solutes. Also, the models require one or more temperature-dependent parameters, which must be obtained from solid solubility data in pure fluids. For these reasons, EoS-based models cannot be easily used to predict solubilities. Several authors have noticed that the logarithm of solid compound solubilities is approximately a linear function of the SCF density. This observation allows the representation of the solubility by using semi-empirical models based on density instead of pressure. These relations are very useful because the knowledge of the above-mentioned physical properties is not necessary.

In this chapter we will focus on the solubility of a pharmaceutical compound, called eflucimibe (Figure 1). Hypocholesterolemic properties of eflucimibe have 


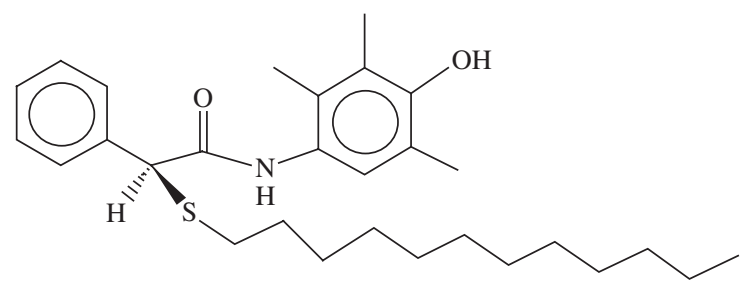

Figure 1 Formula of eflucimibe.

been demonstrated on rabbits and this molecule is therefore a good candidate for becoming an effective drug for hypercholesterolemia therapy. ${ }^{5}$ The empirical formula is $\mathrm{C}_{29} \mathrm{H}_{43} \mathrm{NO}_{2} \mathrm{~S}$, with a corresponding molecular weight of $469.73 \mathrm{~g}$ $\mathrm{mol}^{-1}$.

Its solubility was investigated by means of an original apparatus based on an open circuit analytical method ${ }^{6}$ in pure supercritical $\mathrm{CO}_{2}$ and in supercritical $\mathrm{CO}_{2}$ mixtures with two co-solvents: ethanol and dimethylsulfoxide (DMSO). ${ }^{7}$ Then, these experimental equilibrium solubilities have been correlated using two different density-based models, developed and extended to be applicable to solvent-cosolvent mixtures. ${ }^{8}$

\subsection{Experimental: Equipment and Procedures}

The flow diagram of the apparatus is shown in Figure 2. The main parts of this apparatus are: high-pressure pumps, a mixer, a heater, a heat exchanger, an equilibrium cell, a back pressure regulator, and a separator.

Liquid carbon dioxide is compressed at ambient temperature by means of a syringe pump P1 (Isco, model 260D) at the desired pressure. The eventual cosolvent is introduced by means of another syringe pump P2, in a parallel flow, at a flow rate depending on the desired composition. To achieve a homogeneous mixing of the two liquid solvents, they circulate through a mixer, M. The high-pressure fluid then passes through a heater, $\mathrm{H}$, which is used to heat rapidly the solvent to temperatures over its critical temperature. The SCF then enters into an oven (Spame), where the solubility cell is thermo-regulated. Owing to thermal inertia of the equilibrium cell, its internal temperature is found to be stable within $0.05 \mathrm{~K}$. A heat exchanger, HE, contained in the oven, is used to set the temperature of the solvent at the desired temperature (temperature of the required solubility measurement) before it enters the solubility cell. Downstream the heat exchanger, a 6 way-2 position high pressure Valco valve is placed in the circuit to either direct the SCF to the cell or bypass it. This provides a means for removing eventual solid deposits from the line. Cylindrical in shape, the cell EC contains three compartments placed one above the other and fitted at their bottom with stainless steel fritted disks and O'rings. The solid powder, for which solubility measurements are required, 


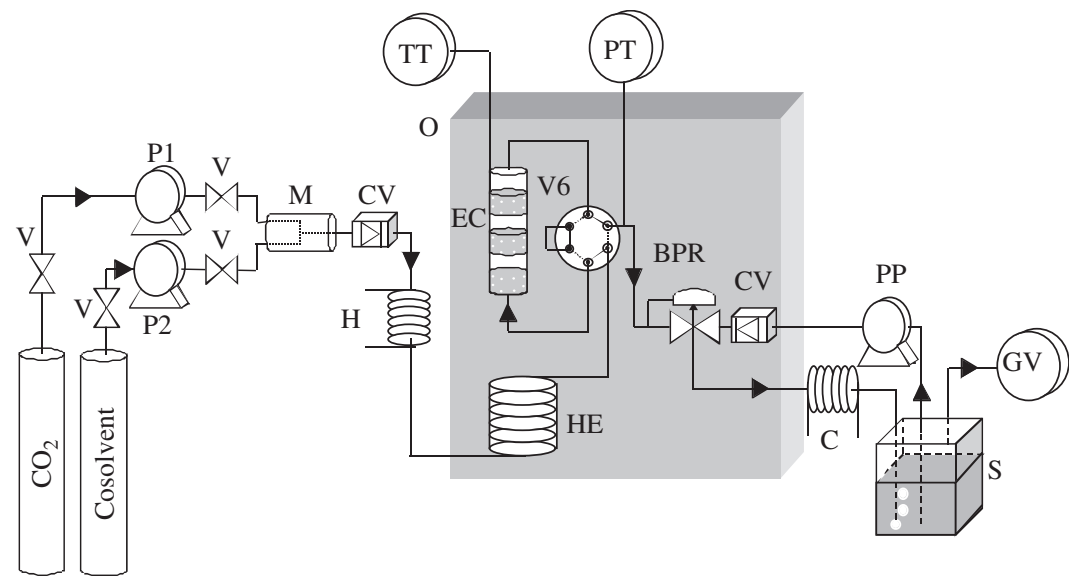

Figure 2 Flow diagram of the apparatus: V: 2 way valves; P1, P2: high pressure pumps; $M$ : mixer; $C V$ : checking valve; $H$ : heater; $O$ : thermostated oven; $H E$ : heat exchanger; V6:6 way-2 position valve; EC: equilibrium cell; TT: temperature transducer; PT: pressure transducer; BPR: back pressure regulator; $C$ : cooler; $S$ : separator; PP: peristaltic pump; GV: gas volumeter.

is put inside the three compartments, which have a total volume of about $5 \mathrm{~cm}^{3}$. The pressure of the supercritical phase is monitored upstream and released downstream through the BPR (Tescom, model 26-1722), which allows a pressure constancy to within $0.5 \%$ in the line. At the outlet of the BPR, the mixture pressure is reduced at the atmospheric pressure, then a recovering liquid solvent (a sufficiently good solvent at atmospheric pressure to recover all the solute) stream is used to get the solute in liquid state for collection. Then, a separator $\mathrm{S}$ is used to vent off the gas and collect the solvent phase. At the end of each experimental run, the liquid solvent line is washed with fresh solvent to recover all the solute. The total volume of used gaseous solvent (extraction solvent), $V_{1}$, is measured by means of a volumeter $\mathrm{GV}$ and the concentration of solid in the solute recovering liquid phase $C_{2}^{L}$ by a gas or liquid chromatography. From these two data and knowing the total volume of the solute recovering liquid solvent, $V^{L}$, the solubility, $y_{2}$, of the solid in supercritical fluid can be calculated through:

$$
y_{2}=\frac{n_{2}}{\sum_{i} n_{i}} \text { with } n_{1}=\frac{V_{1} \rho_{1}}{M W_{1}} \text { and } n_{2}=\frac{C_{2}^{L} V^{L}}{M W_{2}}
$$

$n_{i}, \rho_{i}$, and $M W_{i}$ are respectively the number of moles, the density, and the molecular weight of the compound $i$. The solubility uncertainty depends strongly on the experiment time length: the longer the time, the more accurate are the quantities used in the calculation of the solubility. In consequence, this time length should be optimized to ensure a high degree of accuracy of the result, without too long an experiment time. 
Temperature in the cell is measured directly in its body through a 4-wires 100 $\Omega$ platinum probe, within $0.02 \mathrm{~K}$ as a result of a careful calibration, performed against a $25 \Omega$ reference platinum probe. Pressure is measured in the downstream line of the cell. The pressure transducer (Druck, model PTX611) can measure pressures up to $35 \mathrm{MPa}$ at temperatures up to $400 \mathrm{~K}$, with an accuracy of $4.10^{-3} \mathrm{MPa}$ as a result of a calibration performed using a dead weight balance (Desgranges et Huot, model 5202S CP).

An important requirement in the design of the apparatus was to obtain a saturated stream flowing outside the cell. To confirm the efficiency of the equipment over a large range of operating conditions, measurements have been performed at various flow rates. When in a given range of flow rates, no sensitive effect is observed on the measured solubility values, the equilibrium is confirmed. Separate experiments are required to confirm operating flow rates for each solute of interest.

The validity of the technique was achieved by measuring naphthalene solubility in supercritical $\mathrm{CO}_{2}$. Naphthalene solubility data are very abundant in literature and provide a good base for quantifying tests. The solubility measurements have been found in excellent agreement with previous works. ${ }^{6}$

Eflucimibe was provided by IRPF (Institut de Recherche Pierre Fabre) as a white crystalline powder with a purity greater than $99 \%$. Carbon dioxide, ethanol, and DMSO were of commercial grade.

In addition, we have checked that solvents are really in supercritical state before entering the equilibrium cell. However, little $(P, T, \mathrm{y})$ data is available for the $\mathrm{CO}_{2}$-DMSO binary mixture. Only the data proposed by Kordikowski et al. ${ }^{9}$ is sufficiently complete. The authors have fitted their data using the PengRobinson ${ }^{10}$ equation of state (PR EoS) with two quadratic mixing rules that include two temperature independent binary interaction parameters, $k_{i j}$ and $l_{i j}$. As these authors provide also data for $\mathrm{CO}_{2}$-ethanol binary mixture, we have chosen to use their results in order to have parameters from the same origin for the two co-solvents. The PR EoS has also allowed us to calculate the density of the supercritical fluid, for pure supercritical $\mathrm{CO} 2$ or mixtures with a co-solvent.

\subsection{Solubility in Pure $\mathrm{CO}_{2}$}

The eflucimibe solubility, $y_{2}$, was measured at 308.15 and $318.15 \mathrm{~K}$ (Figure 3). It is noticeable that the values recorded are remarkably low, giving confirmation of the accuracy of the apparatus. The effect of pressure on the solute solubility follows the expected trends, the solubility increasing with pressure for the two temperatures studied. The density of $\mathrm{CO}_{2}$ increases with pressure, the mean inter-molecular distance between $\mathrm{CO}_{2}$ molecules decreases, thereby increasing interaction between the solute and solvent molecules.

The existence of the crossover pressure is well known and illustrated in a number of experimental studies. ${ }^{11}$. The pressure value where the solubility isotherms at various temperatures intersect each other is the result of the competing effects of solute vapour pressure and solvent density. From Figure 3, 


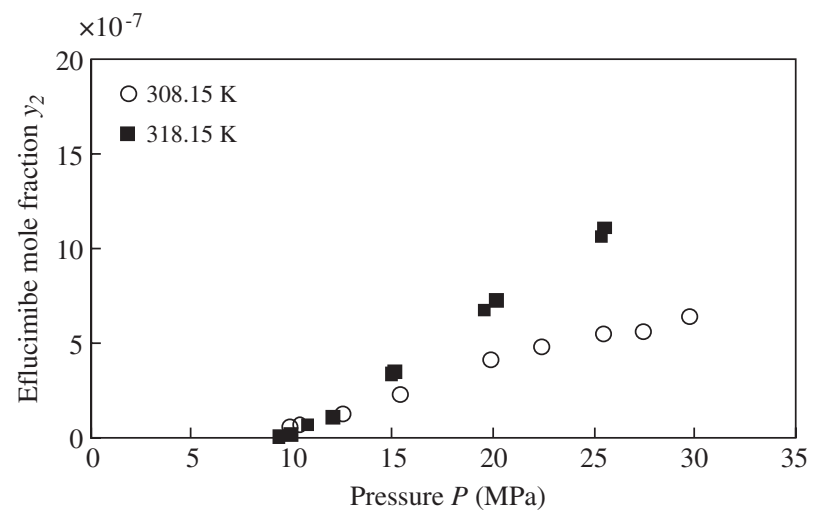

Figure 3 Solubility of eflucimibe in pure supercritical $\mathrm{CO}_{2}$ vs. pressure at 308.15 and $318.15 \mathrm{~K}$.

the crossover pressure can be estimated at about $10 \mathrm{MPa}$. Thus, over the pressure range investigated here, we can consider that solubility is an increasing function of temperature.

\subsection{Ethanol and DMSO Co-Solvent Effects}

Two series of measurements have been performed. The first concerns the influence of $P$ on $y_{2}$, at constant $T$ and constant co-solvent mole fraction $y_{3}$. The solubility has been measured at $318.15 \mathrm{~K}$ for different pressures with $y_{3}=$ 0.05 for ethanol and $y_{3}=0.02$ for DMSO (Figure 4).

The second series of measurements involved the variation of $y_{2}$, as a function of $y_{3}$ at constant $P$ and $T$. The solubility at $318.15 \mathrm{~K}$ and $20 \mathrm{MPa}$ has been measured for different mole fractions of the two co-solvents.

To better illustrate the solubility enhancement, a co-solvent effect $A_{\mathrm{C}}$ is defined as the ratio of the solubility obtained with co-solvent, $y_{2}\left(P, T, y_{3}\right)$, to that obtained without co-solvent at the same temperature and pressure, $y_{2}\left(P, T, y_{3}=0\right)$ :

$$
A_{\mathrm{c}}\left(P, T, y_{3}\right)=\frac{y_{2}\left(P, T, y_{3}\right)}{y_{2}\left(P, T, y_{3}=0\right)}
$$

At $318.15 \mathrm{~K}, A_{\mathrm{C}}$ has been plotted vs. $P$ (Figure 5) and vs. $y_{3}$ (Figure 6). From these figures, it is clear that the solubility is increased by both co-solvents, with however a higher increase with DMSO. For instance, at $20 \mathrm{MPa}$ and $318.15 \mathrm{~K}$, the solubility is 10 times higher with either $6 \%$ of ethanol or $2 \%$ of DMSO, and is multiplied by a factor 50 for about $11 \%$ of ethanol or $3 \%$ of DMSO in the solvent. This solubility enhancement can be attributed to three possible effects: 


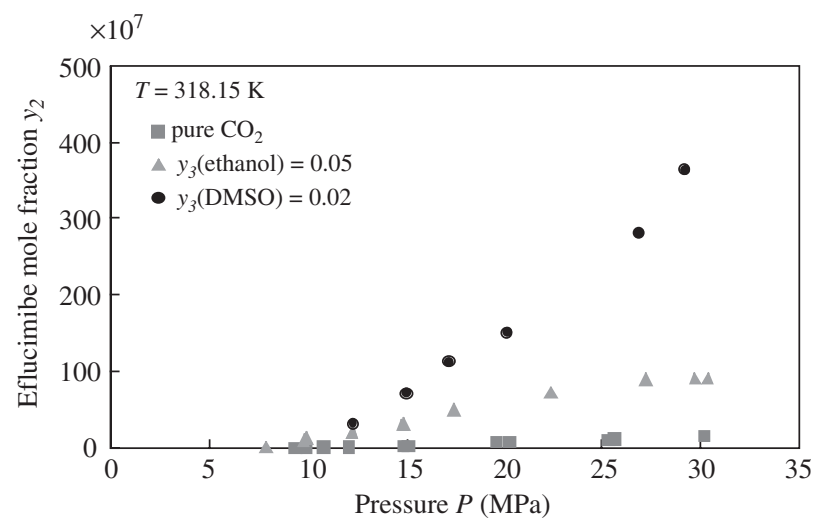

Figure 4 Solubility of eflucimibe in supercritical co-solvent-CO $\mathrm{O}_{2}$ mixtures vs. pressure at $318.15 \mathrm{~K}$ and at constant co-solvent mole fraction.

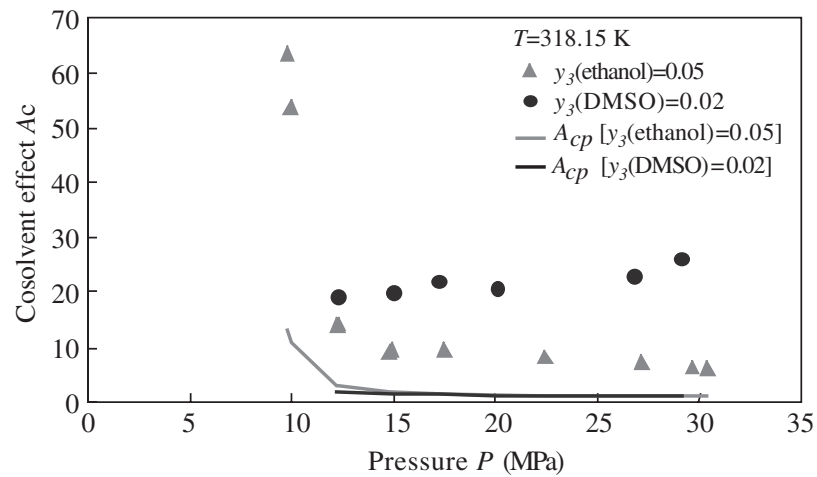

Figure 5 The co-solvent effect in supercritical co-solvent- $\mathrm{CO}_{2}$ mixtures vs. pressure at $318.15 \mathrm{~K}$ and constant co-solvent mole fraction.

increased density of the fluid mixture, modifications in phase equilibria and specific interactions between the solute and co-solvent.

The density contribution to the co-solvent effect is estimated by calculating a co-solvent density effect, $A_{C_{\rho}}$ defined as follows:

$$
A_{C_{\rho}}\left(P, T, y_{3}\right)=\frac{y_{2}\left(P, T, \rho_{f}, y_{3}=0\right)}{y_{2}\left(P, T, \rho_{\mathrm{CO}_{2}}, y_{3}=0\right)}
$$

$A_{C_{\rho}}\left(P, T, y_{3}\right)$ is the co-solvent density effect at $P, T$, and $y_{3}$. It compares the solubility of the solid in pure $\mathrm{CO}_{2}$ at $T$ and $P, y_{2}\left(P, T, \rho_{\mathrm{CO}_{2}}, y_{3}=0\right)$, to that also 


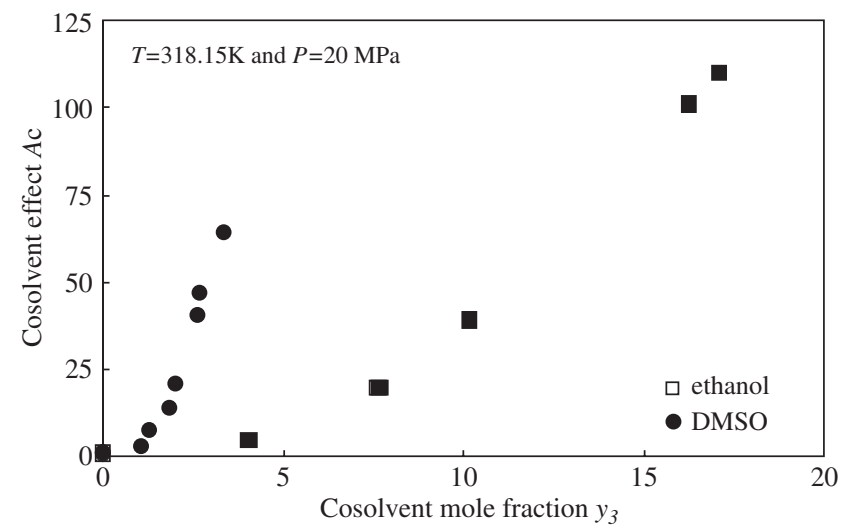

Figure 6 The co-solvent effect in supercritical co-solvent-CO $\mathrm{O}_{2}$ mixtures vs. co-solvent mole fraction at $318.15 \mathrm{~K}$ and $20 \mathrm{MPa}$.

in pure $\mathrm{CO}_{2}$ at the same temperature and pressure but at the density of the mixtures $\rho_{f}$ with a co-solvent mole fraction $y_{3}, y_{2}\left(P, T, \rho_{f}, y_{3}=0\right)$. The cosolvent density effect is represented in Figure 5. It is clear that co-solvent effects cannot be attributed to a density effect alone, neither for ethanol nor for DMSO.

The presence of a co-solvent in a SCF can enhance the melting point depression of a solid solute in a SCF. This effect is usually accompanied by a reduction of the upper critical end point (UCEP) pressure of the system. ${ }^{12}$ This effect is important due to the drastic enhancement of the solute solubility in the vicinity of the UCEP. Unfortunately, the contribution of this effect to the observed co-solvent effect is difficult to estimate because the relevant three phase solid-liquid-gas coexistence curves are not available. However, a qualitative indication of the importance of this effect can be obtained from the examination of the solubility isotherms. ${ }^{13}$ When conditions are close to the UCEP, the slope of the solubility isotherms, $\partial y_{2} / \partial P$, becomes relatively large. An inspection of our solubility isotherms in Figure 6 reveals that as pressure increases, no dramatic variation of $\partial y_{2} / \partial P$ occurs. It may be concluded that cosolvent effects are the result of factors more significant than the proximity of the operating conditions to the UCEP.

The minor contribution of density to the co-solvent effect suggests that chemical forces, rather than physical forces, are responsible for the obtained solubility enhancement. These chemical forces are represented by specific interactions between the solute and the co-solvent. Several authors have observed a linear dependence of $A_{\mathrm{c}}$ with the co-solvent concentration. ${ }^{14,15}$ However, in our experiments, $A_{\mathrm{c}}$ is not a linear function of $y_{3}$, the co-solvent effect increasing more rapidly for higher mole fractions (Figure 6). This different behaviour may be indicative of higher order interactions between the solute and the co-solvent. The type of interaction can be discussed 
qualitatively on the basis of pure component properties as, for instance, solubility parameters. ${ }^{16}$ These parameters describe dispersion, common to all molecules, orientation and induction dipoles forces for polar molecules, and the ability of a species to act as a proton donor or acceptor respectively, for hydrogen bonding.

These parameters show that ethanol is polar and has a high capacity to form hydrogen bonds, being both a proton donor and acceptor (amphiprotic). DMSO is very polar, aprotic but shows a basicity close to that of ethanol.

To identify the potential interactions with the various groups of eflucimibe, co-solvent effects from literature have been examined for compounds characteristic of these groups. However, little data being available for DMSO, we have focused on the co-solvent effect of acetone, which presents some similar properties: it is polar, aprotic and basic. We have chosen results from Ekart et al. ${ }^{14}$ who have studied effects of several co-solvents in ethane. Finally, it seems that the amine and especially the phenol groups play a major role in the solubility increase of eflucimibe, by means of hydrogen bonds. However, despite its higher basicity, ethanol displays a lower co-solvent effect. Clearly, co-solvent basicity is not sufficient to explain the results, thus the dispersion parameter, which is higher for DMSO should also be considered. ${ }^{16}$ The lower co-solvent effect of ethanol might also be explained by the self-association between amphiprotic ethanol molecules, which are no longer available to interact with the solute molecules.

\subsection{Modelling}

The first model was proposed by Chrastil. ${ }^{17}$ This may be considered as a macroscopic description of the surroundings of the molecules in the fluid phase. It is based on the hypothesis that one molecule of a solute $\mathrm{A}$ associates with $\mathrm{k}$ molecules of a solvent $\mathrm{B}$ to form one molecule of a solvato-complex $\mathrm{AB}_{\mathrm{k}}$ in equilibrium with the system. The definition of the equilibrium constant through thermodynamic considerations leads to the following expression for the solubility:

$$
\ln \left(C_{2}\right)=k \ln \left(\rho_{f}\right)+\frac{\alpha}{T}+\beta
$$

where $C_{2}$ is the concentration of the solute in the supercritical phase and $\rho_{f}$ the density of the fluid phase. $k$ is the association number, $\alpha$ depends on the heat of solvation and the heat of vaporization of the solute and $\beta$ depends on the molecular weight of the species. $k, \alpha$, and $\beta$ are adjusted to solubility experimental data.

The second model is based on the theory of dilute solutions, which leads to simple expressions for many thermodynamic properties of dilute near-critical binary mixtures. In particular, Harvey ${ }^{18}$ has obtained a simple linear relationship for the solubility of a solid in a supercritical solvent. Mendez-Santiago and Teja ${ }^{19}$ have approximated this relationship: 


$$
T \ln E=A_{1}+B_{1} \rho_{f}
$$

$E$ is the enhancement factor defined as the ratio between the observed equilibrium solubility and that predicted by the ideal gas law at the same temperature and pressure. $A_{1}$ and $B_{1}$ are adjustable parameters. Finally, in another paper, these authors ${ }^{20}$ have improved the Equation (5) by taking into account the cosolvent mole fraction, $y_{3}$ :

$$
T \ln (E)=A_{2}+B_{2} \rho_{f}+D_{2} y_{3}
$$

$A_{2}, B_{2}$, and $D_{2}$ are three new adjustable parameters.

The quality of all data correlations is quantified by the average absolute deviation $(A A D)$, defined as follows:

$$
A A D=(1 / m) \sum_{i=1}^{m}\left|\left(y_{2, \text { cal }}-y_{2, \exp }\right) / y_{2, \exp }\right|_{i} \times 100
$$

$m$ is the number of data, $y_{2, \text { cal }}$ the calculated solubility value and $y_{2, \exp }$ the experimental one.

\subsection{Extension of the Chrastil Model}

The Equation (4) is first applied to the solubility data of eflucimibe in pure $\mathrm{CO}_{2}$. The two isotherms are well fitted the $A A D$ being less than $8 \%$. The $k$ value obtained shows small temperature dependence. If the data of the two isotherms are gathered before parameter adjustment, the $A A D$ remains practically constant.

The Chrastil model is applicable to pure fluids. Thus, we could apply it to mixtures at constant co-solvent mole fractions, with the hypothesis that these mixtures at constant concentration behave like pure fluids. The new values of $k$ obtained are thus the number of molecules of solvent $k_{1}$ and co-solvent $k_{3}$ associated with one molecule of solute. These numbers are higher than that in pure $\mathrm{CO}_{2}: 7.2$ with $5 \%$ of ethanol and 10.1 with $2 \%$ of DMSO instead of 6.5 in pure $\mathrm{CO}_{2}$. This confirms the importance of specific interactions in the solubility enhancement phenomenon.

\subsection{Generalizing the Mendez-Santiago and Teja Model}

As already done by Mendez-Santiago and Teja, ${ }^{19}$ a Clausius-Clapeyron-type equation is incorporated for the sublimation pressure in Equation (6). However, the Clausius-Clapeyron equation could be advantageously written with the dimensionless logarithm:

$$
\ln \frac{P_{2}^{\text {sat }}}{P^{\text {std }}}=i-\frac{j}{T}
$$

where $P^{\text {std }}$ is the standard pressure (atmospheric pressure equal to 0.101325 
$\mathrm{MPa}$ ). This provides the following correlation with four adjustable parameters $A_{4}, B_{4}, C_{4}$ and $D_{4}$ :

$$
T \ln \left(\frac{y_{2} P}{P^{\text {std }}}\right)=A_{4}+B_{4} \rho_{f}+C_{4} T+D_{4} y_{3}
$$

Equation (9) has directly been applied to all data in pure $\mathrm{CO}_{2}$ as it takes into account the temperature. It provides a good correlation, with an $A A D$ about $6 \%$.

In a first attempt, solubility data are treated independently for each cosolvent, by gathering data at different pressures and co-solvent mole fractions. Data are well fitted, with an $A A D$ about $6 \%$ for ethanol and about $19 \%$ for DMSO. However, data are available at only one temperature, which is not enough to determine correctly the value of the parameter, $C_{4}$, related to temperature. In order to have data at two different temperatures, a second correlation is carried out by gathering data for each co-solvent with that in pure $\mathrm{CO}_{2}$. Finally, the $A A D$ remains constant at about $8 \%$ for ethanol and decreased from 19 to $15 \%$ for DMSO, with coefficients attributed to density, $B_{4}$, and to temperature, $C_{4}$, close to those obtained in pure $\mathrm{CO}_{2}$. It shows that these two coefficients can be considered to be independent of the presence of a co-solvent. It has also to be noted that the value obtained for the coefficient $A_{4}$ remains practically constant in $\mathrm{CO}_{2}$ alone and with a co-solvent. The part of co-solvent effect due to specific interactions between solute and co-solvent is thus independent of density and temperature effects, and is quantified by the value of co-solvent mole fraction coefficient, $D_{4}$. On the basis of these observations, a correlation of all the solubility data of eflucimibe can be carried out by using the following equation with 5 adjustable parameters:

$$
T \ln \left(\frac{y_{2} P}{P^{\text {std }}}\right)=A_{5}+B_{5} \rho_{f}+C_{5} T+D_{5} y_{3}^{\text {ethanol }}+E_{5} y_{3}^{\text {DMSO }}
$$

The data in pure $\mathrm{CO}_{2}$ are treated with: $y_{3}^{\text {ethanol }}=y_{3}^{\text {DMSO }}=0$, and the ones with a co-solvent with: $y_{3}^{\text {DMSO }}=0$ for ethanol as co-solvent and $y_{3}^{\text {ethanol }}=0$ for DMSO as co-solvent. All the data are finally correlated with a value of the $A A D$ less than $13 \%$. This correlation characterizes the solubility of the solid studied in supercritical $\mathrm{CO}_{2}$ by using only one equation: effects of density, of temperature and of each co-solvent are quantified by means of constant values. As previously noted, the effect due to DMSO ( $E_{5}$ at about 38600$)$ is higher than that of ethanol $\left(D_{5}\right.$ at about 9200$)$. By plotting $T \ln \left(y_{2} P / P^{\text {std }}\right)-C_{5} T-$ $D_{5} y_{3}^{\text {ethanol }}-E_{5} y_{3}^{\text {DMSO }} v s$. $\rho_{f}$ all solubility data are gathered on a single line.

\subsection{Conclusion}

The solubility behaviour of eflucimibe was studied in pure supercritical carbon dioxide at 308 and $318 \mathrm{~K}$ between 8 and $30 \mathrm{MPa}$. The solubility appeared to be an increasing function of both pressure and temperature but remained at very low levels. 
The effect of two co-solvents, ethanol and DMSO, was then investigated. The solubility was found to be enhanced by both co-solvents, with however a higher increase with DMSO. The co-solvent effect was found to vary nonlinearly with the co-solvent concentration, showing the importance of specific interactions between the co-solvents and the solute in comparison with density effect. These interactions could qualitatively be explained by means of solubility parameters of co-solvents and of solid functional groups. Finally, hydrogen bonds seem to play the most important role in solubility enhancement. To extend these results, modelling appeared to be necessary to provide a tool for prediction of solid solubilities in supercritical mixtures. A study on densitybased models, in which effects of density, temperature, and co-solvent composition have been quantified was therefore developed.

Solubility data for pharmaceutical solid have been correlated by means of two density - based semi - empirical models: the Chrastil model and the Mendez-Santiago and Teja model.

The application of the two correlations to the data in pure $\mathrm{CO}_{2}$ leads to expressions, which can be used for prediction purposes in a large range of pressure-temperature conditions.

In addition, they have been extended to be applicable to solvent-cosolvent mixtures considered as pure SCF compounds. This work has confirmed the importance of specific interactions in the co-solvent effect. The representation of all the data with two different co-solvents has been carried out with only one relationship by using a generalized Mendez-Santiago and Teja model, in which effects of density, temperature and co-solvent composition are quantified.

\section{Acknowledgments}

The authors would like to acknowledge the financial and technical support of the Pierre Fabre Research Institute (IRPF).

\section{References}

1. J. Fages, H. Lochard, J.-J. Letourneau, M. Sauceau and E. Rodier, Powder Technol., 2004, 141, 219.

2. C. Eckert, D. Ziger, K.P. Johnston and S. Kim, J. Phys. Chem., 1986, 90, 2738.

3. S. Kim and K.P. Johnston, AIChE J., 1987, 33, 1603.

4. R. Fornari, P. Alessi and I. Kikic, Fluid Phase Equilib., 1990, 57, 1.

5. D. Junquero, F. Bruniquel, X. N'Guyen, J.-M. Autin, J.-F. Patoiseau, A.D. Degryse, F.C. Colpaert and A. Delhon, F 12511, Atherosclerosis, 2001, 155, 131.

6. M. Sauceau, J. Fages, J.-J. Letourneau and D. Richon, Ind. Eng. Chem. Res., 2000, 39, 4609.

7. M. Sauceau, J.-J. Letourneau, B. Freiss, D. Richon and J. Fages, J. Supercrit. Fluids, 2004, 31, 133.

8. M. Sauceau, J.-J. Letourneau, D. Richon and J. Fages, Fluid Phase Equilib., 2003, 208, 99. 
9. A. Kordikowski, A.P. Schenk, R.M. Van Nielen and C.J. Peters, J. Supercrit. Fluids, 1995, 8, 205.

10. D.-Y. Peng and D. Robinson, Ind. Eng. Chem. Fundam., 1976, 15, 59.

11. N. Foster, G. Gurdial, J. Yun, K. Liong, K. Tilly, K. Ting, H. Singh and J. Lee, Ind. Eng. Chem. Res., 1991, 30, 1955.

12. M. McHugh and V. Krukonis, Supercritical Fluid Extraction: Principles and Practice, Butterworths, Boston, 2nd edn, 1994.

13. C. Saquing, F. Lucien and N. Foster, Ind. Eng. Chem. Res., 1998, 37, 4190.

14. M. Ekart, K. Bennett, S. Ekart, G. Gurdial, C. Liotta and C. Eckert, AIChE J., 1993, 39, 235.

15. N. Foster, H. Singh, J. Yun, D. Tomasko and S. Macnaughton, Ind. Eng. Chem. Res., 1993, 32, 2849.

16. J. Dobbs, J. Wong, R. Lahiere and K.P. Johnston, Ind. Eng. Chem. Res., 1987, 26, 56.

17. J. Chrastil, J. Phys. Chem., 1982, 86, 3016.

18. A. Harvey, J. Phys. Chem., 1990, 94, 8403.

19. J. Mendez-Santiago and A. Teja, Fluid Phase Equilib., 1999, 158-160, 501.

20. J. Mendez-Santiago and A. Teja, Ind. Eng. Chem. Res., 2000, 39, 4767. 